\title{
JOGO? QUAL JOGO?!
}

\section{Game? Which game?!}

\author{
Ângela Barcellos Café
}

Universidade de Brasília - UnB

Resumo: Contribuições para o dossiê sobre a obra de Spolin no Brasil, relatando experiências de formação docente na UFG e na UnB. Aplico meus estudos de mestrado, para os conceitos e as reflexões em torno do jogo lúdico, relacionando-os aos jogos teatrais de Spolin, nas experiências de estágio no ensino das artes cênicas.

Palavras-chave: Jogos; Formação; Ludicidade.

Abstract: Contributions to the dossier on Spolin's work in Brazil, reporting on teacher training experiences at UFG and UnB. I apply my master's studies, to the concepts and reflections around ludic games, relating them to Spolin's theatrical games, in the internship experiences in the teaching of the performing arts.

Keywords: Theatrical games; Teaching; Playfulness. 


\section{De onde falo}

Fui professora na Escola de Música e Artes Cênicas (EMAC) da Universidade Federal de Goiás (UFG), durante aproximadamente 10 anos, assumindo as disciplinas de Estágio Supervisionado e Didáticas no Ensino das Artes Cênicas para estudantes do curso de licenciatura ${ }^{1}$. Os jogos teatrais de Viola Spolin fizeram parte dessas disciplinas com várias abordagens, dependendo do objetivo desenvolvido, por se aproximarem das pedagogias progressistas que incluem o diálogo e a horizontalidade das relações entre docentes e discentes, considerados neste processo como sujeitos da aprendizagem. Foi essa forma de entender que despertou minha curiosidade para investigar e adotar as obras de Spolin, como proposta metodológica para o ensino de Teatro na escola básica.

Para contribuir com a leitura e proposta dos jogos teatrais de Spolin, trabalho com significados e definições da ludicidade que permeiam essas atividades, estudados no mestrado, aprofundando também os conceitos de jogos, brinquedos e brincadeiras. Este ponto de conexão me aproximou da área com interesse e contribuições que ampliam possibilidades e entendimentos da aplicação dos jogos teatrais para o ensino das artes cênicas, sobretudo na escola de ensino regular.

Nos estudos e práticas dos jogos teatrais de Viola Spolin, encontrei conexões que se encaixavam nas perspectivas de uma educação para a autonomia e transformação, onde o sujeito valoriza seu autoconhecimento e suas ações no mundo respeitando as diferenças entre as pessoas, aprendendo a conviver e produzir juntos, conhecendo suas ações e as consequências desse fazer, contextualizando os saberes envolvidos, formando visões e opiniões críticas a partir do confronto de várias versões de um mesmo tema, tomando atitudes com autonomia e liderança. Enfim, formando sujeitos capazes de perceber seu entorno e atuar na sua comunidade contribuindo para a construção de uma sociedade mais justa, com pessoas ${ }^{2}$ de Direitos.

\footnotetext{
${ }^{1}$ Nessa época (2002), o curso era de Artes Cênicas, sendo modificado para Licenciatura em Teatro alguns anos depois. Lecionei desde a $1^{\text {a }}$ turma de licenciatura, até ser redistribuída para a UnB, em 2016, onde continuo com as mesmas disciplinas, além da pesquisa específica com os contadores de histórias.

${ }^{2}$ Aqui, caberia a expressão: "cidadão" de Direitos, como preconiza o MEC, porque está na LDB. Porém, ao concordar com Chauí (2000) que no Brasil não existem Direitos, pois, dos pobres são retirados e para os
} 
O teatro na escola, infelizmente, ainda é tratado como algo supérfluo ou de menor importância, com poucas chances de expor suas contribuições que são tão amplas. Este relato traz minha compreensão dos "Jogos Teatrais de Viola Spolin" em conexão com ações de uma educação progressista, revelando a abertura da proposta da autora para práticas contemporâneas que atendem as perspectivas de transformação. Entretanto, depende de como cada docente compreende e desenvolve a proposta da autora, ou melhor, de como enfrenta as questões pedagógicas da formação básica.

\section{Abrindo a conversa}

Como professora de Estágio Supervisionado em Goiânia/GO e em Brasília/DF, noto que, por aqui, os Jogos Teatrais de Viola Spolin têm se apresentado como possibilidade para o ensino de Arte/teatro pela maioria dos professores. Nas aulas de Estágio, o primeiro planejamento discente é quase sempre o jogo teatral, como centro das atividades. Isto justifica a importância de refletir essa prática com base em algumas observações.

Trago neste relato um pouco da experiência de como os jogos teatrais de Spolin têm sido utilizados nas escolas de ensino básico, elaborado com base em observações empíricas, realizadas em salas de aula de escolas públicas e privadas, na compreensão docente/discente, nos estudos e explorações do tema por meio das produções dos periódicos e eventos da área, por meio de discussões da disciplina de Estágio, nesses últimos 18 anos.

Acompanho a aplicação dos Jogos Teatrais de Viola Spolin, tanto em sala de aula de graduação entre os licenciandos em formação, como nas escolas de ensino básico por meio dos Estágios Supervisionados, com análises e reflexões sobre a prática docente em construção e sobre o que significa o ensino de teatro na escola regular. Existe uma grande diferença da aula de teatro na escola, quando é projeto ou pertencente à matriz curricular, que é uma outra discussão, que, embora não

ricos são viabilizados. Não passam de privilégios (legalizados). Assim, assumo como resistência evitar o uso da palavra "cidadania" e a obediência à essa contradição. 
caiba no presente texto, deixo apenas a percepção de que os jogos teatrais de Viola Spolin são possíveis e bem vindos aos dois tipos de trabalho na escola. Seja para iniciantes ou para iniciados, seja para conhecer o teatro ou para produzir material de cena, os jogos teatrais de que tratam o presente dossiê são altamente recomendáveis.

\section{Deixando pegadas}

Os jogos teatrais de Viola Spolin se espalharam rapidamente no Brasil. Traduzidos por Ingrid Koudela, se tornaram, talvez, a metodologia do ensino de teatro mais utilizada nas escolas de ensino regular. Ainda que alguns estudiosos prefiram afirmar que não consideram o sistema de jogos teatrais como uma metodologia, percebo que vários professores têm feito essa analogia. Esta afirmação vem dos envolvidos nos estágios curriculares: supervisores (professores das escolas) e estudantes estagiários, levando-me a apurar a escuta a fim de identificar as múltiplas compreensões sobre as aplicações metodológicas dos jogos teatrais em aulas de Teatro. No entanto, isto também seria assunto para outro texto porque não caberia na presente abordagem.

Percebo que, para alguns professores, os jogos teatrais de Viola Spolin são utilizados como metodologia e são a base para todas as aulas. Outras experiências me revelam que os mesmos jogos se ajustam, tanto a metodologias tradicionais, como a metodologias progressistas ${ }^{3}$. Explico essa percepção: segundo a autora, os jogos teatrais são um sistema de ensino, às vezes chamado de abordagem, que considero caber em múltiplas concepções metodológicas e, talvez por isso, haja uma tendência no seu uso como metodologia. Por esse motivo, alerto que, depende da forma pela qual os jogos teatrais são entendidos e trabalhados, de como cada professor assume seu papel de mediador ou de dono do conhecimento.

\footnotetext{
3 Metodologias progressistas são aquelas que buscam uma formação de um sujeito transformador da realidade, crítico, criativo e autônomo, ou seja, capaz de construir sua vida em sociedade, em contraposição às tradicionais metodologias conteudistas que querem as mesmas respostas para as mesmas perguntas priorizando a obediência, a cópia e a alienação, chamada de escola conteudista.
} 
Uma das primeiras confusões que consigo perceber em muitas práticas docentes é que, embora a proposta da autora se direcione à improvisação teatral, muitas vezes é utilizada numa prática do jogo pelo jogo. Ao invés do jogo teatral colher material para montagens de cenas, muitas vezes são utilizados como se todo o fazer teatral se resumisse no jogo teatral. A resultante disso é uma limitação, uma compreensão superficial do teatro como linguagem e como Arte. Na utilização do jogo pelo jogo, conseguimos garantir uma recreação sem alcançar, sequer, a compreensão ou distinção da linguagem teatral. Mas, não é isso que a autora propõe.

O sistema de Jogos de Spolin compreende três partes: Foco, Instrução e Avaliação, que se organizam nesta ordem. O foco ou Ponto de Concentração (POC) traz o objetivo do jogo. Apresenta o problema a ser solucionado. A tarefa do discente é resolver o problema, ou seja, apresentar soluções de atuação possíveis para atingir o objetivo proposto. Este primeiro ponto já difere das pedagogias tradicionais que apresentam um problema já resolvido para cópias e imitações. Os objetivos de ensino estarão envolvidos nesta parte e quando bem planejados levam a bons resultados.

A segunda parte do sistema vai dar segurança para as experiências dos estudantes. É a Instrução, que, por meio da fala do mediador, orienta a aproximação ou distanciamento do POC para a resolução do problema colocado. Aqui, mediadores têm espaço para trabalhar a percepção de cada estudante e da coletividade, ao mesmo tempo. Considero essa parte da Instrução como promotora de uma educação para a 'autonomia', uma vez que não importa a resposta vista de fora por qualquer pessoa, seja docente ou discente, e sim, importa o ponto de vista de quem joga, ou seja, se a própria pessoa que joga sabe perceber seus resultados. Estudantes não precisam ficar esperando palavra final de docentes e para isso dependem da próxima parte que completa o sistema dos jogos propostos por Spolin.

Assim, a Avaliação encerra o processo se certificando da compreensão de quem participou. No início de qualquer sessão de jogos, a turma é dividida em dois grupos que jogarão alternadamente. Enquanto um joga, o outro faz o papel da 
plateia, invertendo os papéis em seguida para ampliar a experiência. Essa subdivisão é mantida inclusive no momento da Avaliação, que se preocupa com o entendimento individual e coletivo ao mesmo tempo. No teatro, temos percepções diferentes do palco e da plateia. A forma de avaliação proposta pela autora encontra eco em propostas atuais de avaliação, em que a orientação se sobrepõe a uma verificação de rótulos, a exemplo de autores como Luckesi (2011) e Benigna (2001). A simples verificação limita o aluno porque não informa o que deve ser modificado, enquanto a avaliação orienta a percepção de estudantes sobre si mesmos, a partir da escuta e da fala do outro.

Considero este um dos pontos mais importantes da proposta da autora, sendo o que a diferencia de outras propostas de jogos teatrais. Primeiro, porque nenhum outro autor propõe uma avaliação de forma sistematizada. Ainda que rodas de conversa sejam feitas após os jogos, na proposta de Spolin, a avaliação tem uma sequência e intenções claras: de esclarecer o jogador quanto à sua atuação, individual e/ou em grupo (dependendo do jogo); revelar o POC quando este não foi bem compreendido durante as ações; abrir espaços para falas de estudantes sobre suas percepções, levando-os a perceberem-se como protagonistas de suas ações e entendimentos; entender os pontos de vistas diferentes de quem está atuando e de quem está na plateia; alcançando a compreensão de que o fazer teatral se dá tanto na atuação como também na recepção. O papel ativo do grupo observador é formador de autonomia e criticidade, uma vez que é dada a oportunidade de Avaliar objetivamente se o problema foi resolvido. Esta perspectiva de avaliação se encaixa perfeitamente nas pedagogias e metodologias conhecidas como progressistas, por considerarem a importância da educação para a autonomia, em que cada estudante é protagonista e responsável por suas aprendizagens. Dessa forma, as técnicas não são impostas nem são modelos, pois emergem naturalmente do jogo, sendo percebida pelos próprios jogadores (SPOLIN, 2005).

Mas, não nos iludamos. Já encontrei práticas de "jogos teatrais de Viola Spolin" que nem de longe se parecem com a proposta da autora, embora o professor diga com todas as letras: "trabalho com os Jogos de Viola Spolin". Para ser mais objetiva, é comum a supressão da avaliação como é proposta pela autora 
causando uma grande perda, pois é justamente essa a ocasião de orientar as próximas ações do grupo e, sobretudo, é esse o momento de tomar consciência de si por meio da percepção do outro e do grupo por meio da fala de todos. Percebo que muitas vezes o uso de jogos populares que pertencem aos diversos exemplos oferecidos pela autora, embora indicados como jogos de aquecimento (SPOLIN, 2007), são oferecidos como únicos nas aulas. Nesses casos se parecem mais com sessões de recreação no lugar de aula ou ensino de Arte/teatro. E, ainda outra forma observada são jogos aleatórios, sem sequência ou um fio condutor que levaria a turma a algum objetivo, ou algum produto artístico que valorize processo.

Outro ponto que liga Spolin às tendências pedagógicas progressistas é sua proposta de "dar problemas para solucionar problemas". São os alunos que têm de achar seu próprio caminho. Arte envolve criação e não resposta pronta. No entanto, alguns equívocos mais comuns que tenho presenciado apontam para essa falta de entendimento, pois a solução já está pronta na cabeça do professor e este faz de tudo para sustentá-la. Isso desloca também a instrução que deveria orientar para o foco, ou seja, para manter o Ponto de Concentração e não para apontar caminhos e resultados prontos. A Instrução é uma parte muito delicada onde encontramos toda a base em que se estrutura a metodologia utilizada pelo mediador ou professor. Os mais tradicionais não conseguem dar espaços para a percepção dos discentes. Querem a resposta da forma que imaginaram tendo dificuldades de lidar com a criatividade e autonomia discente, pois isso dá trabalho, demanda estudo. $\mathrm{A}$ fala direta é uma das ações mais fáceis de perceber e, ainda que seja orientada pela autora em sua proposta, nem sempre é seguida ou entendida por quem a reproduz. Enquanto Spolin orienta para a percepção de cada estudante (e isso me faz entender sua proposta próxima de uma educação para a autonomia), escuto muitas instruções apontando nomes de estudantes e até mesmo interferências em gestos e movimentos, com sugestões que não tem sentido quando vindas de quem está na liderança. São equívocos que, do meu ponto de vista, se afastam bastante da proposta original da autora, embora sejam aplicadas e justificadas em seu nome.

Talvez o que tenha ganhado mais notoriedade na proposta de Spolin seja a forma simples e objetiva que apresenta a estrutura dramática do Jogo Teatral, 
explicada em apenas três palavras, traduzidas nas expressões: “quem?", "onde?”, "o quê?", representadas respectivamente por: personagem, local e ação. Esses três elementos por sua vez são encontrados com frequência em jogos populares de diversas regiões. Ao se deparar com os exemplos da autora identificando-os na riqueza de jogos populares existentes em nossa cultura, a tendência verificada é do uso desses últimos com o nome de jogos teatrais.

Explico melhor. Em meus estudos de mestrado, pude verificar que em muitas culturas diferentes existem diversos jogos semelhantes. O que vai caracterizar a proposta de Spolin não é esse ou aquele jogo, mas o sistema como um todo, tanto na compreensão da estrutura dramática (que, onde, o quê), quanto na aplicação das partes do jogo: foco, instrução e avaliação, respeitando ainda aspectos que promovem a espontaneidade, que é a busca da atuação. Em suas coleções de jogos, apresentados com diversas taxonomias em suas quatro obras, percebemos a presença dos elementos da linguagem cênica ao mesmo tempo em que uma rica diversidade de jogos para o desenvolvimento de habilidades individuais e coletivas para a cena, misturado a jogos provenientes da cultura popular com grande conteúdo dramático.

A experiência de jogar, segundo Spolin (2005), trabalha sete aspectos da espontaneidade, que dão base ao desenvolvimento/formação inicial de atores e atrizes. A autora aponta o jogo como o primeiro aspecto, porém é seu caráter lúdico que propicia liberdade ao jogador, que por sua vez é garantida por outro aspecto que é a aprovação/desaprovação. Viola Spolin (2005) é feliz ao afirmar que a liberdade pessoal está intimamente ligada com o julgamento. De fato, o medo de participar é real na maioria das salas de aula em que o teatro entra pela primeira vez (realidade bem presente). A possibilidade de ser julgado, ou simplesmente de errar, impede qualquer tentativa fora dos padrões já existentes. Vivemos em um mundo midiático cheio de modelos prontos. Porém, a arte não trabalha com essas categorias de certo e errado. No máximo, podemos admitir que alguns resultados não funcionaram para aquele problema de atuação, mas podem funcionar para outro. Outras vezes, é o próprio "erro" que aponta um possível "acerto", afastando o papel policialesco de pedagogias tradicionais que nos fizeram baixar a estima dos 
alunos que erram, ao invés de valorizar suas tentativas, como pesquisadores que são, ou que podem ser, quando estimulados.

Continuando a abordagem dos aspectos, que promovem a espontaneidade, observados por Spolin, a expressão de grupo, tão cara e importante para desenvolver qualquer trabalho coletivo (que é inerente ao teatro), é conquistada durante as práticas, pois as soluções dos problemas exigem coletividade e participação. O que promove essas interações entre estudantes é a plateia, que pertence ao próprio grupo de jogadores e permite, ou melhor, exercita a escuta do outro, colocada em confronto com a sua. Sobre a fisicalização, apontada como aspecto da espontaneidade, o mais importante é mostrar por meio do movimento e do corpo físico, o sentimento da personagem. Isso demanda estudo e prática da experiência.

Como afirma Viola Spolin (2005), a técnica emerge do próprio jogo, não funciona quando é dada de fora para dentro. Os/as estudantes vão se percebendo enquanto jogam. $O$ jogo passa a ser a parte mais importante da aula. Sua compreensão como algo sério, diante da percepção e significados atribuídos à ludicidade, se justifica pela possibilidade de aprendizagem que este traz consigo. Por fim, a autora aponta a transposição do processo para a vida diária como o último desses aspectos, fundamentando as contribuições do ensino de teatro para o diálogo com a vida cotidiana.

Mas, para além das contribuições específicas para o teatro, percebo que o aprofundamento dos conhecimentos em torno do lúdico, do jogo e do brinquedo pode contribuir em duas direções: na ampliação do entendimento e dos resultados das experiências artísticas, seja para o teatro ou para outras linguagens e, por outro lado, no aprofundamento dos significados intrínsecos ao jogo teatral, iniciando pela compreensão dos conceitos de: lúdico, jogo, brinquedo e brincadeira.

\section{Caminhos trilhados}

Meus estudos de mestrado trouxeram a percepção da ausência de compreensão nos conceitos e significados de ludicidade e de jogo, antes do 
entendimento específico do "jogo teatral", criando a possibilidade de uma prática alienada, uma vez que o professor mediador estaria a serviço de algo que ele mesmo desconhece. Ao compreender os significados provocados pelas ações lúdicas, o educador escolhe conscientemente a sua manutenção ou supressão, sabendo quais as possíveis consequências e se posicionando em seus objetivos.

A compreensão do lúdico como um "estado interno do sujeito" (LUCKESI, 2017) afasta seu entendimento enquanto substantivo, tornando sem sentido algumas falas presentes nas escolas, do tipo: "falta lúdico, põe arte", "coloca uma atividade de arte, que é lúdica!". Obviamente, pode ser artística e lúdica, mas, além disso, poderia ser arte e não ser lúdica. E poderia ainda ser matemática ou qualquer outra área e ser lúdica também. Para o autor, o que vai garantir a ludicidade é a disponibilidade para um momento de alegria, vivenciado com uma liberdade que pressupõe a escolha interna do sujeito. Apenas a pessoa que brinca pode internamente escolher se aquela atividade, naquele momento, é lúdica ou não.

A manifestação lúdica é inerente ao ser humano (HUIZINGA, 1971) e está em seu interior, podendo ser expressa ou simplesmente sentida internamente, sem aparência exterior. O que vai garantir a possibilidade da ação lúdica é a livre escolha que, por sua vez, é um dos elementos fundantes do Jogo. É importante discernir o que é jogo e o que é lúdico, pois onde tem jogo, tem lúdico. Porém, o inverso não é garantido, haja vista que existem outras atividades que podem ser lúdicas e não pertencerem à categoria de jogo, como por exemplo: nadar, ler, e uma infinidade de atividades que afetam as pessoas de diferentes maneiras. $O$ jogo de que trata este estudo, portanto, é o jogo lúdico, ou seja, aquele jogo que envolve também o brinquedo ou a brincadeira. Este jogo lúdico pode contrapor-se, por exemplo, ao desporto competitivo, popularmente conhecido como jogo. Outras formas de jogo já estudadas também estão fora do foco presente, que se direciona para o contexto da ludicidade vivenciada no interior do jogo, brinquedo ou brincadeira.

A opção por usar indistintamente essas três categorias: jogo, brinquedo e brincadeira foi assumida por mim com base nos estudos dos autores de várias 
áreas do conhecimento. Neste estudo ${ }^{4}$, foi proposta a divisão dos autores em dois grupos: aqueles que usam indistintamente as três terminologias e aqueles que definem o jogo na presença de regras, o brinquedo como material físico do brincar e a brincadeira como ação do brincar. Os autores que desconsideram essas diferenças, explicam, por exemplo, que a presença de regras já é presente na brincadeira do faz de conta, mostrando como a criança vai aprendendo as coisas do mundo na participação da vida social. Quanto ao brinquedo ser um material físico, percebemos um impasse: o próprio corpo é um brinquedo (VYGOTSKY, 1998) e não poderia ser confundido com um material. Seria o corpo brinquedo ou brincadeira? Discussão no mínimo complexa que exige outros caminhos de investigação.

Portanto, sem discordar das diferenças existentes entre jogo, brinquedo e brincadeira, assumi lidar com os três termos indistintamente, considerando-os como espaços propícios à manifestação lúdica. É a compreensão desse tipo de jogo no espaço da escola que me interessa.

A compreensão da ludicidade exige o reconhecimento de cada contexto em suas formas diversas, ou seja, uma compreensão historicamente situada, como propõe Marcellino (1990). Nessa compreensão, reconhecemos uma desvalorização das atividades lúdicas em contraponto às atividades produtivas, consideradas como sérias, já apontadas por Huizinga (1971). Por esse motivo, é comum nas escolas atuais a preferência pelos trabalhos sérios em detrimento das atividades lúdicas. Mas, essa seriedade é vinculada a uma produtividade da lógica de mercado, por isso a ludicidade é hoje aceita na educação infantil e é ainda recusada nas outras fases escolares. Sendo o teatro o berço do "Jogo Teatral", como se percebe nas práticas atuais, é visível sua desvalorização. Entretanto, diversos estudiosos ${ }^{5}$ do tema, em diferentes áreas do conhecimento, apontam a

\footnotetext{
${ }^{4}$ Pesquisa, coordenada pelo prof. Dr. Nelson de Carvalho Marcellino, na Unicamp, na área dos estudos de Lazer, na Faculdade de Educação Física, nos anos de 1998 a 2000, que tive a oportunidade de participar.

5 Estudos e experiências que envolvem aspectos e/ou atividades lúdicas podem ser encontrados em: Rousseau; Froebel; Montessori; Claparède; Pestalozzi; Dewey; Decroly; Cousinet; Makarenko; Brougère; Wallon; Vygotsky; Piaget; Chateau.
} 
importância não só da manifestação lúdica, mas sobretudo do valor do jogo em outros temas relacionados às questões postas a uma educação atual.

Entre os estudos mais reconhecidos, Huizinga (1971) define o jogo como:

uma atividade livre, conscientemente tomada como 'não séria' e exterior à vida habitual, mas ao mesmo tempo capaz de absorver o jogador de maneira intensa e total. É uma atividade desligada de todo e qualquer interesse material, com a qual não se pode obter qualquer lucro, praticada dentro de limites espaciais e temporais próprios, segundo uma certa ordem e certas regras. Promove a formação de grupos sociais com tendência a rodearem-se de segredos e a sublinharem sua diferença em relação ao resto do mundo por meio de disfarces ou outros meios semelhantes. (1971, p. 16)

É este conceito que tomo como base para minhas práticas e reflexões constantes no exercício da formação docente. Sobretudo na última frase da citação de Huizinga (1971), os Jogos teatrais se identificam de forma específica, pois provocam uma coesão do grupo, que fica rodeado de segredos e liberdades internas. Clima necessário à criação artística e a uma educação que se quer transformadora.

\section{O que ficou, por enquanto...}

Não gosto de conclusões, pois estas podem trazer certezas que ficariam cristalizadas e impediriam novas criações. Considerando a dinamicidade da cultura e do fazer humano na arte, prefiro pensar em arremates provisórios com possibilidades de futuras transformações, ficando no por enquanto... Jogando o jogo!

Ao eleger o sistema dos jogos teatrais de Viola Spolin para ser aplicado ao ensino de Teatro na educação básica, vários pontos se destacam na contribuição de uma formação que considera a autonomia e o poder de transformação da sociedade como centros das questões educacionais. Trata-se, por exemplo, de não deixar a manifestação lúdica ser sufocada, pois é da natureza humana e da espontaneidade natural da pessoa. Para a valorização do lúdico, é imprescindível 
a aceitação do jogo na escola. Mais que aceitação, reconhecimento de seu potencial. Quando bem planejado, o jogo é muito bem acolhido no ambiente escolar, pois, ao contrário do que se pensa, o jogo é ordem e criar ordem e a escola perde muito ao considerá-lo como indisciplina, acabando por não conseguir conter o excesso de energia das crianças e/ou adolescentes.

Outro ponto é a alteridade própria das questões tratadas pela área da linguagem teatral. A especificidade do trabalho coletivo presente no teatro e a variação de papéis e contextos podem ampliar a visão de mundo de estudantes, levando-os/as a novos conhecimentos e possibilidades de inserção na vida social e no trabalho. Essa alteridade é amplamente exercitada no jogo teatral, da forma como é proposto por Viola Spolin.

Quanto aos relacionamentos interpessoais, na aceitação e compreensão dos limites do outro, ficam mais abertos, pois os jogos teatrais exigem uma interação e inclusão em que estudantes precisam uns dos outros e acabam criando laços e vínculos de solidariedade, às vezes para o resto da vida. Aprendem a reconhecer e respeitar seus limites e as fronteiras a sua volta.

O funcionamento do jogo ensina a importância de se tomar atitudes para resolver os problemas colocados, mantendo o foco no objetivo que se quer. Por isso é uma educação para a autonomia, haja vista que não se pede cópias e sim novas soluções. Por isso, estimula protagonismo, atitude e muitas vezes liderança.

Embora o jogo não possa ser considerado como única possibilidade para o ensino de teatro na escola básica, sem dúvida é uma das pedagogias mais ricas para recolher materiais dos próprios alunos para a encenação, contribuindo grandemente com a criatividade e autonomia discente.

Aos professores que acreditam e utilizam Viola Spolin em seus trabalhos, que continuemos na busca por aprofundamentos e diálogos que ampliem possibilidades de uma formação crítica e transformadora por meio da Arte/teatro. 


\section{Referências}

BENIGNA. As dimensões do projeto político pedagógico: novos desafios para a escola. São Paulo, Papirus, 2001.

CAFÉ, Ângela Barcellos. Dos contadores de histórias e das histórias dos contadores. Goiânia: Cegraf/UFG, 2005.

HUIZINGA, J. Homo Ludens. São Paulo, Perspectiva, Edusp, 1971.

Koudela, I. D. Jogos teatrais. São Paulo: Perspectiva, 1984.

LUCKESI, Cipriano Carlos. Verificação ou avaliação: o que pratica a escola? In: LUCKESI, Cipriano Carlos. Avaliação da aprendizagem escolar: estudos e proposições; 22. Ed. São Paulo: Cortez, 2011.

Marcellino, N. C. Pedagogia da animação. Campinas, SP: Papirus, 1990.

SPOLIN, V. Jogos Teatrais: o fichário de Viola Spolin. São Paulo: Perspectiva, 2001.

SPOLIN, V. Improvisação para o teatro. São Paulo: Perspectiva, 2005.

SPOLIN, V. Jogos teatrais na sala de aula: livro do professor. São Paulo: Perspectiva, 2007.

SPOLIN, V. O jogo teatral no livro do diretor. São Paulo: Perspectiva, 2008.

VYGOTSKY, L. S. A formação social da mente: o desenvolvimento dos processos psicológicos superiores. São Paulo: Martins Fontes, 1998.

CHAUÍ, Marilena. Convite à Filosofia. Disponível em: https://edisciplinas.usp.br/pluginfile.php/1936981/mod resource/content/3/aula\%2 01 CHAU\%C3\%8D\%2C\%20Marilena.\%20Convite\%20\%C3\%A0\%20Filosofia.pdf Acesso em 13/09/2018.

LUCKESI, C. C. Ludicidade e atividades lúdicas: uma abordagem a partir de experiências internas. Disponível em: http://luckesi002.blogspot.com.br/2015/08/14-desenvolvimento-dos-estadosde.html. Acesso em 09/02/1018. 